\title{
Peak power shaving in hybrid power supplied 5G base station
}

\author{
Lee Jia Woon, Gobbi Ramasamy, Siva Priya Thiagarajah
}

Faculty of Engineering, Multimedia University, Cyberjaya, Malaysia

\section{Article Info}

Article history:

Received Feb 3, 2020

Revised Apr 13, 2020

Accepted Jul 9, 2020

\section{Keywords:}

Energy efficiency

Fluctuation of demand

Hybrid power supply system

Poor power quality

Solar energy

\begin{abstract}
The Information and Communication Technology sector consumes approximately $3 \%$ of the world's electrical energy due to the exploding demand for internet service. The most energy-intensive part of cellular communications is the base station, which there are about four million of them deployed globally. As Fifth Generation (5G) wireless networks are introduced, the number of base stations will be growing in parallel with the data traffic which in turn will increase the energy consumption of the base station to cater for the growing capacity. The high-power consumption and dynamic traffic demand overburden the base station and consequently reduce energy efficiency. In this paper, an energy-efficient hybrid power supply system for a $5 \mathrm{G}$ macro base station is proposed. It is analysed that with the solar energy working in conjunction with the conventional supply from the grid, the reduction of poor power quality is observed as the fluctuation of the demand is greatly decreased. The proposed model showed a reduction in the average grid power by $14.9 \%$. Furthermore, the power supply showed peak power shaving of $5 \mathrm{~kW}$; thus, reducing the reliance on the grid as well as increased the energy-efficient of this hybrid power supply system.
\end{abstract}

This is an open access article under the CC BY-SA license.

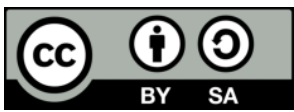

Corresponding Author:

Siva Priya Thiagarajah,

Faculty of Engineering, Multimedia University,

Persiaran Multimedia, 63100 Cyberjaya, Selangor, Malaysia.

Email: siva.priya.thiagarajah@mmu.edu.my

\section{INTRODUCTION}

Around $3 \%$ of the world's electrical energy is consumed by the Information and Communication Technologies (ICT) sector [1]. The power consumption of ICT will double every four to five years [2]. Mobile telephone exchange, core network, data centre, base stations, and retails form the ICT sector. However, base stations are the most energy-intensive parts of the ICT sector. An average 5G base station consumes approximately $11,577 \mathrm{~W}$, a shocking $68 \%$ increment from the energy consumption of a $4 \mathrm{G}$ base station [3]. Thus, improving the energy efficiency of the $5 \mathrm{G}$ base station is critical and has been the centre of recent research [4]. With the ever-increasing demand for network services [5], more than four million base station are expected globally. The energy consumption will proportionally increase as these base stations account for about $57 \%$ of the total consumed energy in cellular networks [4]. While $32 \%$ of base station power is consumed by other vital components of a base station; digital signal processing, the cooling system and power supply unit [6], it is worth noting that the energy consumption of the components varies depending on the type of base station (macro, micro, femto, pico) [7]. The power consumption of each component can be classified into two categories: load-dependent component and load-independent component. Load-independent components like the cooling system, microwave link and rectifier have constant power consumption while load-dependent components like the power amplifier, digital signal processing and transceiver have fluctuating power demand. Studies have been done in a few works to show 
the direct relation of the energy consumption to load-dependent components [8-10]. The power consumption of a base station consists of two parts: static power consumption and dynamic power consumption [11]. The total power consumption of a base station can be expressed. The load-independent components constitute the static part of power consumption, and the load-dependent components constitute dynamic power consumption.

$$
P_{\text {total }}=P_{\text {static }}+P_{\text {dynamic }}
$$

The load/traffic of a base station varies according to the number of users and service that are used in the base station; hence, the highly variable energy consumption of a base station is generally unpredictable unless a real-time measurement is done. With the unpredictable demand of the base station, balancing the supply from the grid and demand from the consumer must be done in real-time, as mismatching of supply and demand can threaten the integrity of the grid over extensive areas within seconds [12]. The power grid must respond quickly to the varying demand which will result in system failures, considerable losses, and high energy bills. The direct savings to consumers of good power quality is lower energy cost and reactive power tariffs. The condition of poor power quality of the supply is otherwise, whereby this condition can last for milliseconds or up to hours [13]. The causes for poor grid power quality is lightning strikes, poor power factor, reactive power to supply network, surges and harmonics created by the equipment, non-linear and fluctuating loads, harmonic pollution and voltage variations.

The complexity in power-electronic technology creates a lot of the presence of harmonics in the power grid. Harmonics distorts current and voltage waveforms of the supply. Non-linear load such as rectifier, inverter, voltage controllers and frequency converters produce harmonics in a power supply network. The base station is also a non-linear load that introduces harmonics into the power grid as the power supply system of a base station consists of several power electronics technology such as single-phase rectifiers, inverter and more [14]. The power from the grid commonly supplies sinusoidal current. Hence, when the non-linear load draws power from the grid, the load impedance varies with the supplies voltage and draw non-sinusoidal current that carries harmonic content. This harmonic content will create voltage distortion, which may affect the other connected loads in the same supply network. There are two categories of voltage variation, namely, short-duration voltage variation and long-duration voltage variation. Voltage dip or sag, spike or surge and swells are the example form of short-duration voltage variation. At the same time, fluctuation/flickers, undervoltage, overvoltage and interruption are the example form of long duration voltage variation. Thus, these causes of poor power quality are the major contributor to the severe impact on the supply network. The base station, which is a non-linear load, is one of the systems connected to the supply network that consumes imbalance electrical power which may affect other installations on the supply network or the mobile network operator (MNO) itself, in the form of penalties imposed by the utility company. According to IEC 61000 series standards, poor power quality is due to the compatibility problem [15]. Hence, levelling out the peaks loads is slowly emerging into the ICT sector as a prominent solution to address the energy efficiency issue in a base station. Reducing the power consumption of the 5G base station by finding an alternative for a short period to avoid a spike in consumption due to the dynamic nature of the load will undoubtedly reduce the poor power quality issues to the grid. The short-term demand spike in the base station will result in a high possibility of the maximum demand charge from the utility to MNO, similar to the issue faced by most of the industrial consumer. Thus, peak power shaving is required in a $5 \mathrm{G}$ base station as it is foreseen that the hike in power consumption and the increasing number of traffic can cause a short duration demand spike.

Supplying power to a base station becomes more complex and diverse as there are multiple energy supplying sources and methods that are introduced to the site. The base station is typically powered up purely by one type of source, namely the power grid or diesel generators with or without battery banks. Extensive scale utilisation of solar energy in the $5 \mathrm{G}$ era is foreseen, given its ability for continuous power generation and cost reduction [16]. The studies in [17] and [18] proposed a solar-diesel hybrid to reduce the dependency of diesel source at a remote area with the battery acting as back-up power to the system. With the help of solar energy, the diesel consumptions were reduced to about $82.05 \%$, which ultimately reduced the OPEX to $63 \%$. Solar-wind hybrid system with different types of back-up power such as diesel generators and combination of different kinds of batteries (lead-acid, redox-flow and lithium-ion) has also become a prominent method to power up a GSM/UMTS base station [19]-[21]. Authors in [22] purely utilised the solar renewable energy and batteries bank to power up an LTE macro base station, whereby the energy-efficient, realistic energy profile and as well as optimising the cost was discussed. The study in [23] highlights feasibility of utilising solar-only with batteries as back-up power using a solar-based $100 \%$ green site. The positive outcome was that the base station would be running most of the time and the battery state-of-charge (SOC) remain high most of the time.-Different types of storage system such as lithium-ion battery (LiB), fuel 
cell technologies and hydrogen-based technology have been implemented with solar panels by different authors [24-26]. Considering the cost, ability to act as a reliable long-term energy storage system, size of the site and harmful emission impact, LiB is deemed to be a prominent solution as back-up power. Alternatively, solar panel and a set of batteries are deployed together with the connection from the power grid to power up an LTE macro base station [27]. It is concluded that utilising both renewable energy and the power grid can reduce the cost as much as $75 \%$ depending on the energy production of the solar panels. However, most of the works appeared in the context of optimising the economic impact. Still, few of the works appeared in the context of improving energy-efficient of the power system for the next-generation wireless communication. While all past studies analysed the various hybrid power options to power up the $5 \mathrm{G}$ base station, not the conclusive research was done on the load profiling of the $5 \mathrm{G}$ base stations. Load profiling is critical because the generation of power supply to a base station highly depends on the demanded load. Thus, analysing the energy profile is essential to ensure that the supply will be reliable, always available, and stable to meet the demand. The existing solutions do not directly apply to provide an energy-efficient power supply system for a $5 \mathrm{G}$ macro base station. The contributions of this work, therefore are:

- Load profiling for 5G macro base station.

- Peak power shaving for 5G macro base station using a hybrid power supply system.

\section{RESEARCH METHOD}

The proof of concept (POC) is a speed test and measurement exercise between a test user equipment (TUE) and a non-standalone architecture (NSA) 5G macro base station installed on the roof of the Faculty of Engineering, Multimedia University, Cyberjaya, Selangor, Malaysia. Raw binary files of roughly 20GB in size were used in testing to ensure that the speed was consistently up at maximum throughput during the test. A Fluke Megger Logger is connected to the input of the power supply system, as shown in Figure 1, to study the energy profile of the $5 \mathrm{G}$ macro base station. The power consumption measurement of the $5 \mathrm{G}$ testbed is taken for four days. From the timestamp, transferring a single 20GB file takes up approximately 15-20 minutes, and the power consumption of the $5 \mathrm{G}$ testbed was measured within that time frame. The power vs time graph when a 20GB file was transferred is shown in Figure 2. Based on (1), the static power consumption of the testbed is about $1.9 \mathrm{~kW}$ and the increment of power when there is an activity (dynamic power) of transferring a single $20 \mathrm{~GB}$ file is around $100 \mathrm{~W}$.

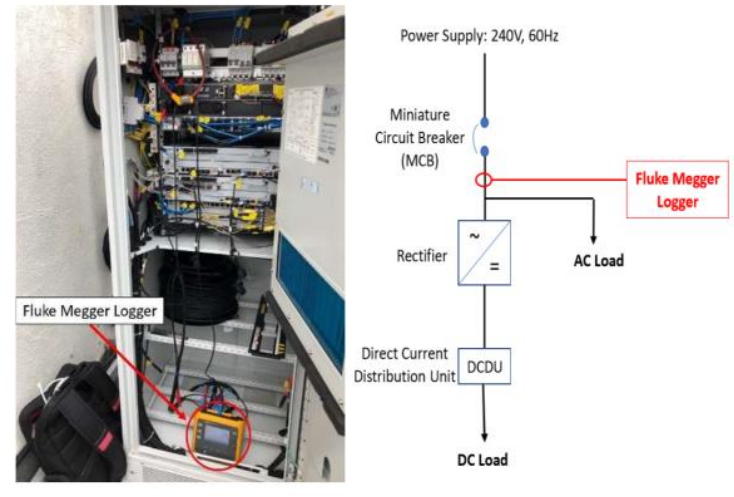

Figure 1. Connection of the fluke megger logger

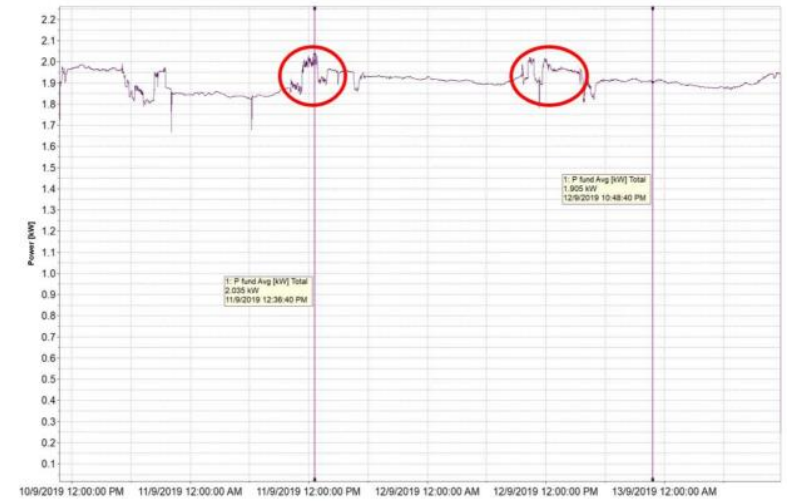

Figure 2. Power consumption measurement of the $5 \mathrm{G}$ testbed for four days

As the measurement was taken from the $5 \mathrm{G}$ testbed purely consist of TUE as the only traffic for the base station, a few data and assumption need to be made to construct the energy profile for a 5G macro base station. The work assumed that each of the user connected to the base station was utilising the maximum throughput of single traffic (transferring of a 20GB file). Hence, the dynamic power consumption per traffic was $100 \mathrm{~W}$, which then multiplied by the number of users and added up to the static power of $1.9 \mathrm{~kW}$ for each time interval. At the same time, the maximum power consumption of this macro base station was assumed to be $11 \mathrm{~kW}$ to support the coverage and capacity, as reported in [3]. Based on the assumption made, the energy profile of the $5 \mathrm{G}$ macro base station was constructed. It was analysed that there will be a high possibility of rising and fall of power demand from time to time, depending on the number of users utilising the services of 
the base station shown in Figure 3. The high variable demand of the base station will be difficult for the utility to match the demand which brings poor power quality issue to the grid due to high voltage drop that results in penalties imposed by the utility. Hence, an energy-efficient hybrid power supply system is proposed to cater to the $5 \mathrm{G}$ load profile.

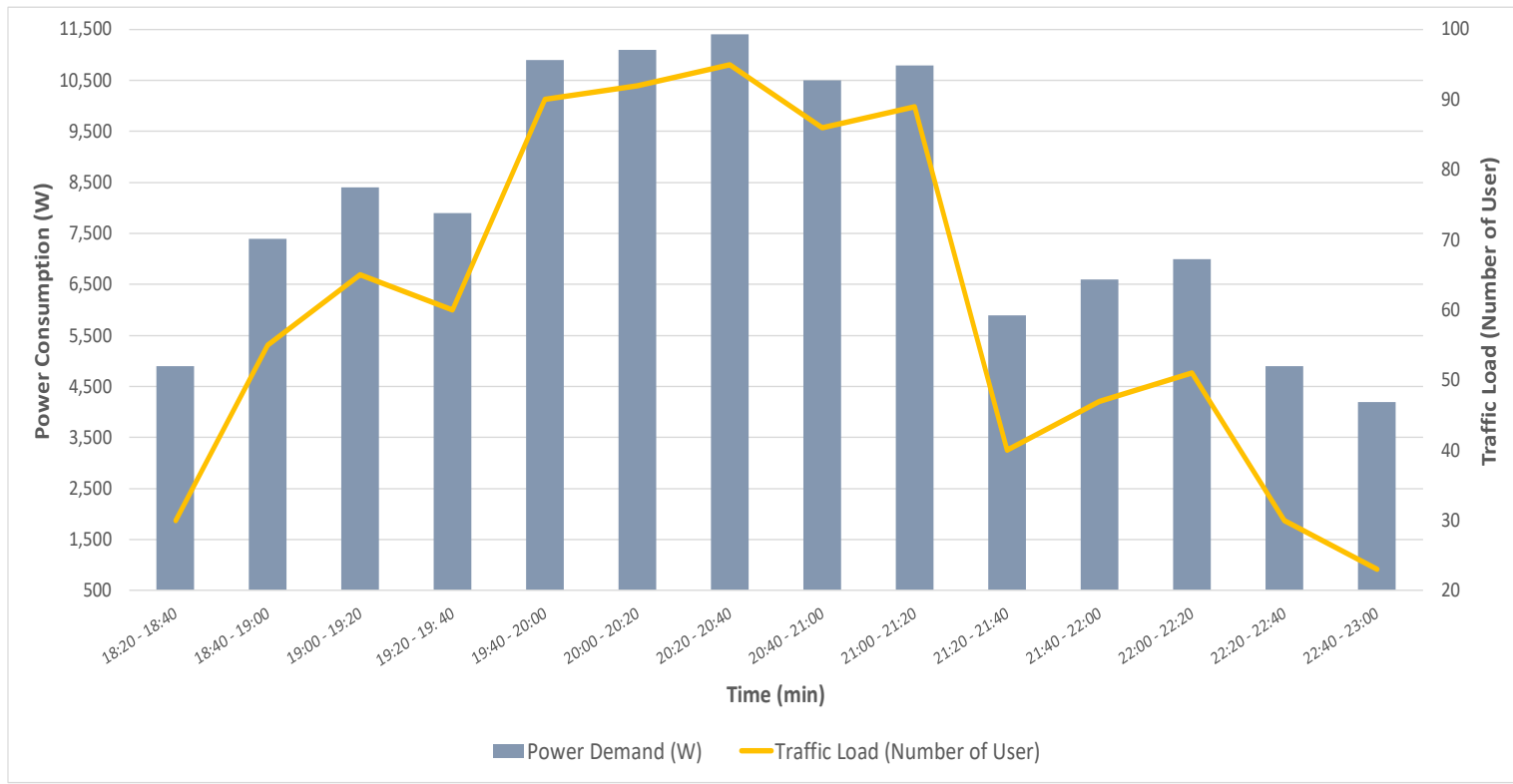

Figure 3. Energy profile for $5 \mathrm{G}$ macro base station

Figure 4 shows the design of a hybrid power supply system for the $5 \mathrm{G}$ macro base station. The hybrid power supply system consisted of the power grid, solar panels, Maximum Power Point Tracking (MPPT), bi-directional inverter, batteries, and solar inverter. The solar PV has a batteries bank for numerous purposes, including storing the excess energy as well as discharging when the power generation from solar energy is insufficient (i.e. cloudy weather or during night-time). Due to the unpredictable ambient temperature and solar radiation of the site, an MPPT controller harvests the maximum available power from the solar panels incorporated in this hybrid system. The solar controller uses an MPPT scheme applied using the modified perturbation and observation algorithm. According to the roadmap for solar energy, the efficiency of the PV panel is predicted to become three times more than the present efficiency by 2030 [28]. Furthermore, the cost per watt generated is expected to reduce by $50 \%$. The use of renewable also reduces the carbon footprint. According to the Kyoto protocol, mobile network operators are challenged to reduce the energy consumption as the protocol will likely to be implementing regulation of limiting per-nation carbon dioxide emission [29]. The main objective of employing solar energy is to reduce the dependency on the grid energy whereby the energy bill cost and the impact on the grid will be reduced. Since the generated power highly depends on the load, the dynamic energy consumption of the base station due to the variation of the traffic load might cause instabilities to the power grid. Utilising solar renewable energy can reduce the usage of on-grid power as well as satisfying the demanded energy by limiting the variation of on-grid energy consumption.

The proposed hybrid power supply limit the grid power to be supplying a maximum of $6 \mathrm{~kW}$ in order to reduce the energy consumption from the power grid. The maximum power provided from the solar energy will be $5 \mathrm{~kW}$ assuming that the peak power of the load to be around $11 \mathrm{~kW}$. The additional algorithm running on the MPPT controller enables the power flow from solar PV when the baseload of $6 \mathrm{~kW}$ is exceeded. Whenever the solar energy generated is more than required, the surplus will be directed to the battery. However, when the load does not exceed the baseload of $6 \mathrm{~kW}$, then the grid will be the only source of power. The simulation model of this hybrid power supply solution is done using MATLAB Simulink and was analysed based on two cases: Case 1: standalone power grid and Case 2: proposed hybrid power supply system. 


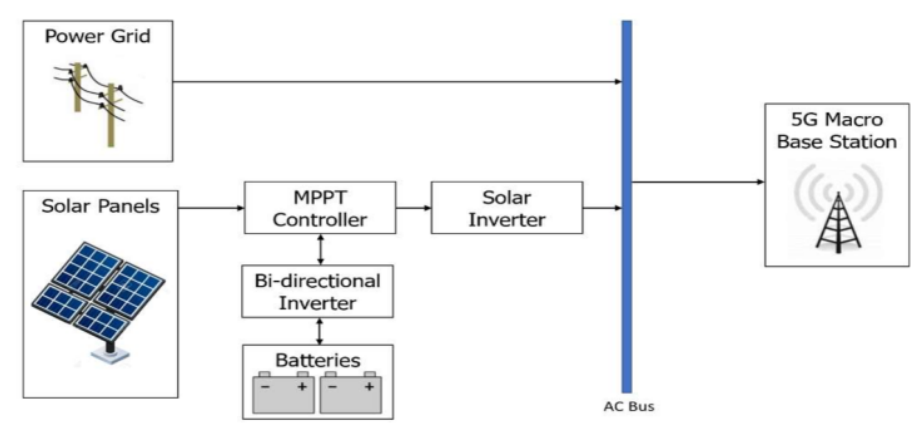

Figure 4. General proposed architecture of the hybrid power supply system

\section{RESULTS AND DISCUSSION}

\subsection{Case 1: standalone power grid}

The slight difference in the supply and demand shown in Figure 5 is due to the low power factor of the circuit. Ideally, when the power delivered is completely consumed by the load, then the power factor will be $1(100 \%)$. Practically, it is only possible if the load is linear and purely resistive, which will result in the voltage and current to be in phase. In this research, the circuit consists of an inductor which affects the power factor of the system. Furthermore, inductor stores energy when current passes through; this stored energy in the inductor results in differences between maximum and minimum power points of the single-phase supply (power grid) and dynamic load. Therefore, the average daily power drawn from the grid is approximately $6 \mathrm{~kW}$ or $144 \mathrm{kWh}$. The high energy requirement and fluctuation in demand load will seed a higher probability of the contribution of poor power quality to the grid. As $5 \mathrm{G}$ macro base station is one of the contributors of poor power quality problem to the supply network, it will cause an increment of system losses, receive penalties imposed by utilities for polluting the supply network, unexpected power supply failures as well as the affecting other loads such as factories, industrial plants and residence.

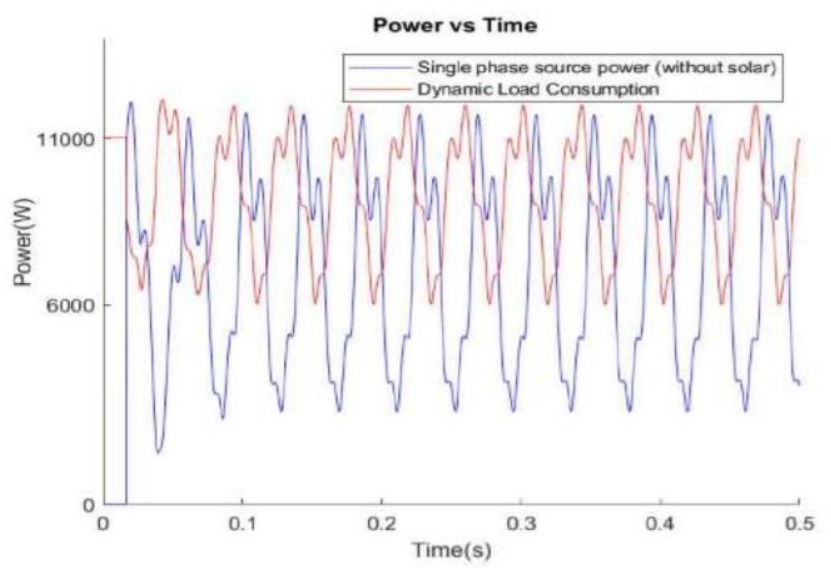

Figure 5. Power delivered by the single-phase supply without the presence of solar energy

\subsection{Case 2: proposed hybrid power supply system}

In this research, the hybrid power supply solution of solar energy and a single-phase supply source is simulated in MATLAB Simulink. The dynamic load in the simulation fluctuates at about $11 \mathrm{~kW}$ to $6 \mathrm{~kW}$ to ensure that the single-phase supply and the solar PV modules will only supply a maximum of $6 \mathrm{~kW}$ and $5 \mathrm{~kW}$, respectively. Comparing Figure 5 and Figure 6, it shows that with the presence of solar energy, the fluctuation of the maximum power delivered by the single-phase source is around $200 \mathrm{~W}$ as compared to the fluctuation without the presence of solar energy, which is around $5.5 \mathrm{~kW}$. Integrating solar energy into the power supply system greatly mitigates the rise and fall of the power from the grid, which possibly reduce the possibility of mismatching of supply and demand. The reason that the single-phase supply source fluctuates slightly beyond $6 \mathrm{~kW}$ is due to the resistance accuracy of the limiting resistor connected in series with the source. In order to verify that the single-phase supply and the solar PV is working together to satisfy the load 
demand, the analysis was made based on the power from the single-phase source, solar PV array, as well as the dynamic load. At the instant of $0.08 \mathrm{~s}$, approximately $8.8 \mathrm{~kW}$ is required to power up the load; the singlephase source will supply around $6.2 \mathrm{~kW}$ while the solar PV will supply about $2.4 \mathrm{~kW}$ which add up to be around the demand load.

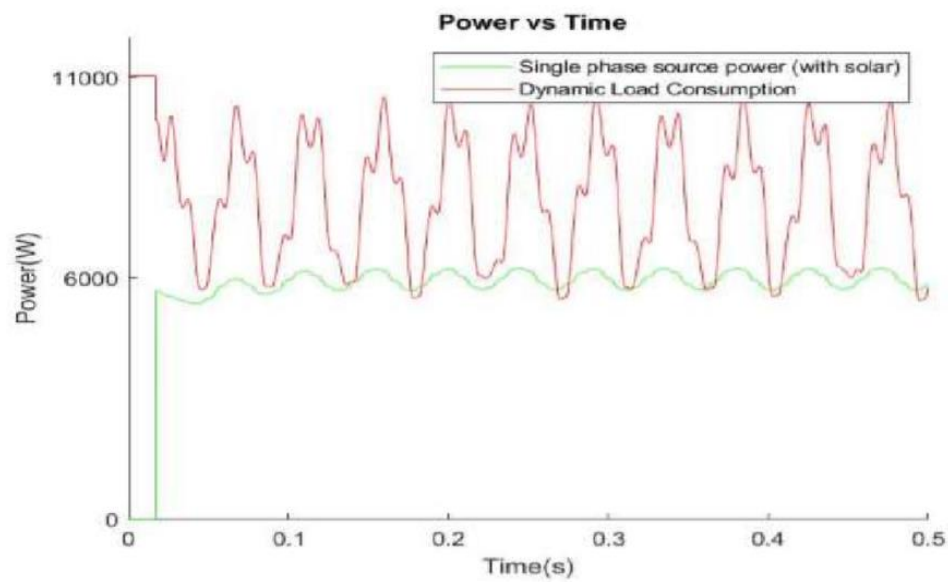

Figure 6. Power delivered by the single-phase supply with the presence of solar energy

The results showed that single-phase supply which mimics the power from the grid only needed to provide about $5.7 \mathrm{~kW}(137 \mathrm{kWh} /$ day $)$. In comparison, without the presence of solar energy, the single-phase supply required to supply approximately $6.7 \mathrm{~kW}(161 \mathrm{kWh} /$ day $)$. The base station is a non-linear load, hence, decreasing the fluctuating demand from the power grid will reduce the contribution of poor power quality problem to the power grid that can impact the other loads which are connected to the same supply network. The mismatching of supply and demand will cease the operation of the base station and suuch mismatches will be less likely to happen by utilising the proposed system.

\subsection{Cost-saving analysis}

The maximum power required to be generated by the solar panel is $5 \mathrm{~kW}$. The price per $\mathrm{kW}$ is approximately RM 5,000, whereby the cost of investment will be around RM 25,000. Table 1 projects the commercial summary pricing. In Malaysia, commercial consumers are charged a tariff of RM 0.509 per $\mathrm{kWh}$, and an Imbalance Cost Pass-Through (ICPT) of RM 0.025 per $\mathrm{kWh}$. Consumers who install solar panels, can convert these two costs into savings. Additionally, electricity generation from renewable energy sources in Malaysia is charged RM 0.00814 per kWh. Based on the Return of Investment (ROI) chart, it shows that the payback period will be 4.12 years.

Based on these savings, the annual savings for a single $5 \mathrm{G}$ macro base station is RM 4,336. Table 2 projects the annual savings for some of the MNO in Malaysia (Company A and Company B), based on their existing total number of 4G LTE base station which will soon be accompanied by the deployment of $5 \mathrm{G}$ base station. The estimation was made based on the average lifetime of the solar panel, which is 25 years. Other factors were considered, such as, Operation and Maintenance (O\&M) costs which will reduce the projected annual savings. It is assumed there will be four visits yearly to maintain the excellent performance of the system.

Table 1. Commercial summary pricing analysis-cash model

\begin{tabular}{llll}
\hline \multicolumn{1}{c}{ Description } & \multicolumn{1}{c}{ Value } & \multicolumn{1}{c}{ Description } & Value \\
\hline Total DC System Size & $5.0 \mathrm{kWp}$ & KWTBB Rate per kWh & MYR 0.008 \\
Price per kWp & MYR 5,000 & Year-1 TNB Savings & MYR 4,336 \\
Total System Price/ Cost of & MYR 25,000 & Average Monthly Year-1 TNB & MYR 361 \\
Investment & & Savings & MYR 1,094 \\
Daily Specific Yield & $4.38 \mathrm{kWh} / \mathrm{kWp} /$ Day & Average Yearly O\&M Cost & MYR 27,338 \\
Annual Specific Yield & $1,598 \mathrm{kWh} / \mathrm{kWp} /$ Year & Total 25 Years O\&M Cost & MYR 12,000 \\
Annual Generation & $7,990 \mathrm{kWh} /$ Year & Total 25 Tax Savings/Exceptions & MYR 137, 932 \\
Average Monthly Generation & $666 \mathrm{kWh} / \mathrm{Month}$ & Total 25 Years Savings & MYR 97, 594 \\
Tariff per kWh & MYR 0.509 & Total 25 Years Net Savings & 4.12 Years \\
ICPT per kWh & MYR 0.026 & Payback Period & \\
\hline
\end{tabular}




\begin{tabular}{ccc}
\multicolumn{2}{c}{ Table 2: Annual Savings for some of the MNO in Malaysia } \\
\hline & Number of LTE base station & Annual savings \\
\hline Company A & 3,453 & MYR 14, 972, 208 \\
Company B & 3,421 & MYR 14, 833, 456 \\
\hline
\end{tabular}

\section{CONCLUSION}

At present, energy-efficiency of a base station is becoming a critical concern due to the increment of power consumption in the latest generation, 5G. Among all the key areas of approaches and technologies to achieve an energy-efficient 5G macro base station, the power supply technologies and the energy flow management approach were highlighted. In this study, a load profiling for $5 \mathrm{G}$ macro base station was conducted. Furthermore, a proposed hybrid power supply solution for the $5 \mathrm{G}$ macro base station was designed based on the analysis of the $5 \mathrm{G}$ energy profile obtained whereby the load is highly variable and has the possibilities fluctuating within few thousand Watts. This proposed solution utilises PV solar energy alongside the traditional supply from the grid. The effectiveness of the proposed solution was demonstrated by two case studies. The first case, a $5 \mathrm{G}$ base station, solely depends on the power from the grid. While in the second case, the proposed system is utilised whereby the solar energy is integrated with the grid. The results clearly showed the reduction in the maximum power demand of a base station from $11 \mathrm{~kW}$ to $6 \mathrm{~kW}$, which is about $45 \%$ cutback. The findings of the study further emphasise that introducing green energy as a solution to achieve the goal of an energy-efficient base station is expected to be playing an essential role in the $5 \mathrm{G}$ era. For instance, one of Malaysia's MNO can save up to RM 15 million annually with the existing total number of 3,453 4G LTE base station which will soon be accompanied by the deployment of $5 \mathrm{G}$ base station. Introducing such a hybrid power supply solution along with governments' initiatives towards using renewable energy, it is expected to reach a greener and energy-efficient deployment of 5G base stations.

\section{ACKNOWLEDGEMENTS}

This work has been conducted partly in the framework of the Research Project titled "Second life EV battery for Energy Storage System" which is funded by Malaysia Electricity Supply Industry Trust Account, Ministry of Energy and Natural Resources, Malaysia.

\section{REFERENCES}

[1] I. Humar, X. Ge, L. Xiang, M. Jo, M. Chen and J. Zhang, "Rethinking energy efficiency models of cellular networks with embodied energy," in IEEE Network, vol. 25, no. 2, pp. 40-49, March-April 2011.

[2] J. Lorincz and T. Matijevic, "Energy-efficiency analyses of heterogeneous macro and micro base station sites," Computers \& Electrical Engineering, vol. 40, no. 2, pp. 330-349, 2014.

[3] Huawei Technologies Co., "5G Power Whitepaper," pp. 1-15, 2019.

[4] M. H. Alsharif, J. Kim, and J. H. Kim, "Green and sustainable cellular base stations: An overview and future research directions," Energies, vol. 10, no. 587, pp. 1-27, 2017

[5] P. K. Malik, D. S. Wadhwa, and J. S. Khinda, "A Survey of Device to Device and Cooperative Communication for the Future Cellular Networks," International Journal of Wireless Information Networks, vol. 27, pp. 411-432, 2020.

[6] A. Ayang, P.-S. Ngohe-Ekam, B. Videme, and J. Temga, "Power Consumption: Base Stations of Telecommunication in Sahel Zone of Cameroon: Typology Based on the Power Consumption-Model and Energy Savings," Journal of Energy, vol. 2016, no. 3161060, pp. 1-15, 2016.

[7] K. Samdanis, P. Rost, A. Maeder, and Meo, "Green Communications: Principles, Concepts and Practice," WILEY, 2015.

[8] M. S. Dahal, J. N. Shrestha, and S. R. Shakya, "Comparison \& Measurement of Energy Efficiency of Micro and Macro Base Stationsin Nepal Using Regression Model,” Journal of Green Engineering, vol. 7, no. 4, pp. 505-526, 2018.

[9] J. D. Gadze, S. B. Aboagye, and K. A. P. Agyekum, "Real Time Traffic Base Station Power Consumption Model for Telcos in Ghana," International Journal of Computer Science and Telecommunication, vol. 7, no. 5, pp. 6-23, 2016.

[10] J. Lorincz, T. Garma, and G. Petrovic, "Measurements and modelling of base station power consumption under real traffic loads," Sensors, vol. 12, no. 4, pp. 4281-4310, 2012.

[11] O. Arnold, F. Richter, G. Fettweis and O. Blume, "Power consumption modeling of different base station types in heterogeneous cellular networks," 2010 Future Network \& Mobile Summit, Florence, pp. 1-8, 2010.

[12] U S Department of Energy, "Benefits of Demand Response in Electricity Markets and Recommendations for Achieving Them," U.S. Dep. Energy, no. February, pp. 1-93, 2006.

[13] D. O. Johnson, "Issues of Power Quality in Electrical Systems," International Journal of Energy and Power Engineering, vol. 5, no. 4, pp. 148-154, 2016. 
[14] K. Roshan Milani, B. Adham, M. R. Banaei and F. Mohajel Kazemi, "Measurement and analysis of base transceiver stations power quality parameters and assessment of its unfavourable effects on Iran distribution systems," in CIRED - Open Access Proceedings Journal, vol. 2017, no. 1, pp. 761-765, 102017.

[15] Fuad Faisal.M, “Understanding Power Quality Standards," Suruhan Tenaga, p. 88, 2011.

[16] Hua Wei Technologies Co. Ltd, "5G Telecom Power Target Network White Paper, " pp. 1-22, 2019.

[17] M. A. B. M. Salihoddin et al., "Hybrid Power Supply System for Telecommunication Base Station," 2018 2nd International Conference on Smart Sensors and Application (ICSSA), Kuching, pp. 80-83, 2018.

[18] J. Kaldellis, I. Ninou, and D. Zafirakis, "Minimum long-term cost solution for remote telecommunication stations on the basis of photovoltaic-based hybrid power systems," Energy Policy, vol. 39, no. 5, pp. 2512-2527, May 2011.

[19] P. Nema, S. Rangnekar and R. K. Nema, "Pre-feasibility study of PV-solar / Wind Hybrid Energy System for GSM type mobile telephony base station in Central India," 2010 The 2nd International Conference on Computer and Automation Engineering (ICCAE), Singapore, pp. 152-156, 2010.

[20] S. Hashimoto, T. Yachi and T. Tani, "A new stand-alone hybrid power system with wind generator and photovoltaic modules for a radio base station," INTELEC 2004. 26th Annual International Telecommunications Energy Conference, Chicago, IL, USA, pp. 254-259, 2004.

[21] G. Merei, C. Berger, and D. U. Sauer, "Optimisation of an off-grid hybrid PVWind-Diesel system with different battery technologies using genetic algorithm," Solar Energy, vol. 97, pp. 460-473, 2013.

[22] M. A. Marsan, G. Bucalo, A. Di Caro, M. Meo and Y. Zhang, "Towards zero grid electricity networking: Powering BSs with renewable energy sources," 2013 IEEE International Conference on Communications Workshops (ICC), Budapest, pp. 596-601, 2013.

[23] D. Valerdi et al., "Intelligent energy managed service for green base stations," 2010 IEEE Globecom Workshops, Miami, FL, pp. 1453-1457, 2010.

[24] M. Nakamura and K. Takeno, "Green Base Station Using Robust Solar System and High Performance Lithium ion battery for Next Generation Wireless Network (5G) and against Mega Disaster," 2018 International Power Electronics Conference (IPEC-Niigata 2018 -ECCE Asia), Niigata, pp. 201-206, 2018.

[25] D. Rekioua, S. Bensmail, and N. Bettar, "Development of hybrid photovoltaic-fuel cell system for standalone application," International Journal of Hydrogen Energy, vol. 39, no. 3, pp. 1604-1611, 2014.

[26] B. Shabani and J. Andrews, "Standalone solar-hydrogen systems powering Fire Contingency Networks," International Journal of Hydrogen Energy, vol. 40, no. 15, pp. 5509-5517, 2015.

[27] Y. Zhang, M. Meo, R. Gerboni, and M. Ajmone Marsan, "Minimum cost solar power systems for LTE macro base stations," Computer Networks, vol. 112, pp. 12-23, 2017.

[28] "IEA webstore. Technology Roadmap - Solar Photovoltaic Energy 2014." [Online]. Available: https://webstore.iea.org/technology-roadmap-solar-photovoltaic-energy-2014. [Accessed: 12-Jan-2020].

[29] United Nations, "Kyoto Protocol to the United Nations Framework Convention on Climate Change (United Nations),"pp. 1-20, 1998

\section{BIOGRAPHIES OF AUTHORS}

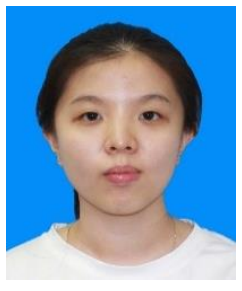

Lee Jia Woon is currently pursuing her M.Sc. in Engineering in Multimedia University, Malaysia (MMU). She obtained her B.Eng. (Hons) Electrical from MMU in 2020 and is currently pursuing her master's in engineering science in MMU. Her research interests include future electricity grids and the integration of renewable energy source. She is an active member and volunteer of the Institute of Electrical and Electronics Engineers (IEEE) and Institution of Engineers Malaysia (IEM).

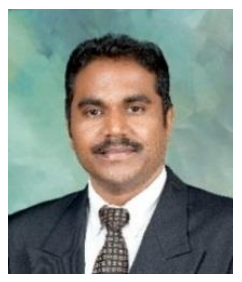

Gobbi Ramasamy received the B.Eng (Electrical), MSc (Tech) and Ph.D (Eng) degrees in 1998, 2001 and 2008 respectively. He has been associated with technical education for more than twenty years. He is a consultant providing solutions for many problems associated with electric motors, drives system and energy management for various industries. His research interests are in the reliability of electric motors, motor drives system and solar power application. Dr. Gobbi is a corporate member of the Institution of Engineers Malaysia, a professional engineer registered to Board of Engineers, Malaysia, and a Senior Member of IEEE, US.

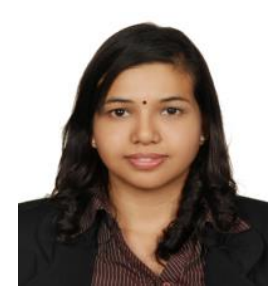

Siva Priya Thiagarajah is Lecturer at the Faculty of Engineering, Multimedia University (MMU). She received a Bachelor's in Electrical Engineering (Telecommunications-Hons) from Technology University of Malaysia and Master of Engineering (Telecommunications) from MMU. She is currently pursuing her Ph.D. in Engineering in MMU. She is a Professional Engineer with Practicing Certificate with Board of Engineers Malaysia and a Corporate Member with the Institution of Engineers Malaysia. Prior to joining the academia, she worked in interference resolution, spectrum management and satellite procurement. Her research interests include satellite communications, wireless channel modelling/optimisation, IoT, and biomedical applications. 